\title{
High Strength Ni-Fe-W and Ni-Fe-W-P Alloys Produced by Electrodeposition
}

\author{
Jamil Ahmad*, Katsuhiko Asami, Akira Takeuchi, Dmitri V. Louzguine and Akihisa Inoue \\ Institute of Materials Research (IMR), Tohoku University, Sendai 980-8577, Japan
}

$\mathrm{Ni}-\mathrm{Fe}-\mathrm{W}$ alloys were produced by electrodeposition from an ammoniacal citrate bath having nickel sulphate, ferric sulphate and sodium tungstate as sources of nickel, iron and tungsten, respectively. The alloys prepared at low current densities have nanocrystalline structure, while those prepared at high current densities are amorphous. X-ray diffraction results show that the structure changes gradually from nanocrystalline to amorphous phase with an increase of current density. As the current density increases, tungsten content increases while iron content decreases. The hardness of the alloys increases with increasing tungsten content. The best mechanical properties among all the alloys are obtained for $51 \mathrm{Ni}-$ $29 \mathrm{Fe}-20 \mathrm{~W}$ alloy prepared at $600 \mathrm{~A} / \mathrm{m}^{2}$. Effect of sodium hypophosphite on the composition of the alloys produced at $2000 \mathrm{~A} / \mathrm{m}^{2}$ was also studied. Addition of hypophosphite causes a decrease in tungsten content of the alloys. Further increase in the hypophosphite content causes a decrease of both iron and tungsten contents and an increase of phosphorus and nickel contents. For the alloys deposited from solutions containing sodium hypophosphite more than $0.03 \mathrm{~mol} / \mathrm{L}$, the total molar content of tungsten and phosphorus remains constant at 20 at $\%$.

(Received June 9, 2003; Accepted July 25, 2003)

Keywords: nickel, iron, tungsten, phosphorus, nanocrystalline, amorphous

\section{Introduction}

Amorphous and nanocrystalline alloys are characterized by unique and highly attractive mechanical, ${ }^{1-5)}$ electrochemical, $^{6-11)}$ magnetic $^{12-19)}$ and catalytic ${ }^{20-23)}$ properties. Electrodeposition offers an easy and less expensive route to produce these alloys in controlled thickness, shapes and sizes, mostly in net-shape forms. Tungsten alloys with iron group metals are important for their good mechanical properties. A lot of work has been done on binary alloys of tungsten with iron group elements. ${ }^{24-29)}$ There are also some reports on ternary alloys having two iron group elements with tungsten. However, with the aim of exploring alloys with much improved mechanical and magnetic properties, there is still strong need to investigate these ternary alloy systems more deeply and also to study higher order alloy systems.

In our previous work we reported the electrodeposition of Ni-W-P alloys with high strength properties. ${ }^{30)}$ It was observed that sodium hypophosphite, which was used to introduce phosphorus in the system, had negative effect on the tungsten content of the alloys. The tungsten content was decreased sharply by the addition of sodium hypophosphite. Therefore, it was difficult to produce alloys with high phosphorus content as well as high tungsten content. In the present study we intend to develop tertiary Ni-Fe-W-P alloys with high phosphorus and tungsten contents. An interesting feature of these alloys is that we can produce Ni-Fe-W-P alloys in which the ratio of $\mathrm{W} / \mathrm{P}$ can be intentionally controlled in a constant total content of 20 at $\%$.

\section{Experimental Procedures}

The composition of the plating solution used for electroplating is shown in Table 1. For the incorporation of nickel and iron, their respective sulphates were used. Tungsten was introduced in the form of sodium tungstate and sodium hypophosphite was used as a source of phosphorus. Ammonium chloride and sodium citrate were used as complexing

*Corresponding author, E-mail: mirza@imr.tohoku.ac.jp
Table 1 Bath composition and preparation parameters for electrodeposition.

\begin{tabular}{ll}
\hline Basic bath composition & \\
\hline $\mathrm{NiSO}_{4} \cdot 6 \mathrm{H}_{2} \mathrm{O}$ & $0.06 \mathrm{~mol} \cdot \mathrm{L}^{-1}$ \\
\hline $\mathrm{FeSO}_{4} \cdot 7 \mathrm{H}_{2} \mathrm{O}$ & $0.057 \mathrm{~mol} \cdot \mathrm{L}^{-1}$ \\
\hline $\mathrm{Na}_{3} \mathrm{C}_{6} \mathrm{H}_{5} \mathrm{O}_{7} \cdot 2 \mathrm{H}_{2} \mathrm{O}$ & $0.5 \mathrm{~mol} \cdot \mathrm{L}^{-1}$ \\
\hline $\mathrm{Na}_{2} \mathrm{WO}_{4} \cdot 2 \mathrm{H}_{2} \mathrm{O}$ & $0.14 \mathrm{~mol} \cdot \mathrm{L}^{-1}$ \\
\hline $\mathrm{NH}_{4} \mathrm{Cl}$ & $0.5 \mathrm{~mol} \cdot \mathrm{L}^{-1}$ \\
\hline $\mathrm{NaBr}$ & $0.15 \mathrm{~mol} \cdot \mathrm{L}^{-1}$ \\
\hline $\mathrm{NaH}_{2} \mathrm{PO}_{2} \cdot \mathrm{H}_{2} \mathrm{O}$ & $0-0.15 \mathrm{~mol} \cdot \mathrm{L}^{-1}$ \\
\hline Operating conditions & \\
\hline Temperature & $348 \mathrm{~K}$ \\
\hline $\mathrm{pH}$ & 8.5 \\
\hline Current density & $100-2000 \mathrm{~A} \cdot \mathrm{m}^{-2}$ \\
\hline
\end{tabular}

agents, while sodium bromide was added to improve the conductivity of the solution. Copper coupons of surface area $\sim 2.3 \times 10^{-4} \mathrm{~m}^{2}$ were used as substrate. Platinum electrode was used as counter electrode and cathodic potential was measured against saturated calomel electrode (SCE). The deposition was performed under constant current conditions using a Hokuto Denko HZ-3000 Potentio-galvanostat in galvanostatic mode. The copper coupons were first mechanically ground on $\mathrm{SiC}$ grinding papers up to 2000 grit and then polished on polishing wheel using $0.05 \mu \mathrm{m}$ alumina paste. They were then cleaned in acetone on ultrasonic vibrator to completely remove alumina particles. Then they were dipped in dilute sulphuric acid solution for 20 seconds, washed in distilled water and used for electroplating. $\mathrm{pH}$ of the solution was set at 8.50 at the start of experiments.

The weight of the electroplated alloy was determined by measuring the difference between the weight of the coupon just before and after electroplating. Hardness of the films was measured with a UMIS-2000 nano-indentor hardness tester. Structure was determined by X-ray diffraction (XRD). The chemical composition was determined with a scanning 
electron microscope (SEM, Hitachi S-800) equipped with Kevex energy dispersive spectroscopy (EDS) system as well as an Electron Probe Microanalyser (EPMA, Jeol 8621-MX).

\section{Experimental Results}

\subsection{Ni-Fe-W alloys}

Figure 1 shows the composition of ternary Ni-Fe-W alloys as a function of current density. One can see a decrease in nickel content and an increase in tungsten content with increasing current density from 100 to $1000 \mathrm{~A} / \mathrm{m}^{2}$. However, the iron content remains almost constant from 100 to $1000 \mathrm{~A} /$ $\mathrm{m}^{2}$. In this range the tungsten content increases in conjunction with a decrease of nickel content. The nickel content becomes approximately constant in the high current density range of 1500 to $2000 \mathrm{~A} / \mathrm{m}^{2}$, though tungsten and iron contents are also approximately constant. However, the tungsten content is much higher than the Fe content in this range. The error bars in Fig. 1 represent the surface compositional variation of the alloy films. The composition was determined randomly at five different positions lying far from each other. The variation in tungsten content on the surface of each film was negligible. The variations in iron and nickel contents were also slight except for the alloys deposited at the current densities from $700-1000 \mathrm{~A} / \mathrm{m}^{2}$.

The structure of the alloys was determined by XRD. Figure 2 shows the XRD patterns of some typical alloys. The alloy deposited at $100 \mathrm{~A} / \mathrm{m}^{2}$ shows diffraction peaks of $\mathrm{Fe}_{2} \mathrm{~W}$ (103), FeNi (111), FeNi (200) and FeNi (220). For the other alloys deposited at higher current densities, one can see only one single peak which is very close to FeNi (111). This single peak shifts towards higher angles with an increase in current density. The peak width also increases with increasing current density due to a decrease in grain sizes of the alloys deposited at higher current densities. The alloys deposited at $400 \mathrm{~A} / \mathrm{m}^{2}$ or higher current densities show quite broad diffraction peaks due to the formation of an amorphous phase. However, the broadening of the peaks is very gradual. It seems that the structure changes from nanocrystalline to heterogeneous structure consisting of amorphous plus nanocrystalline phases, and then to a completely amorphous

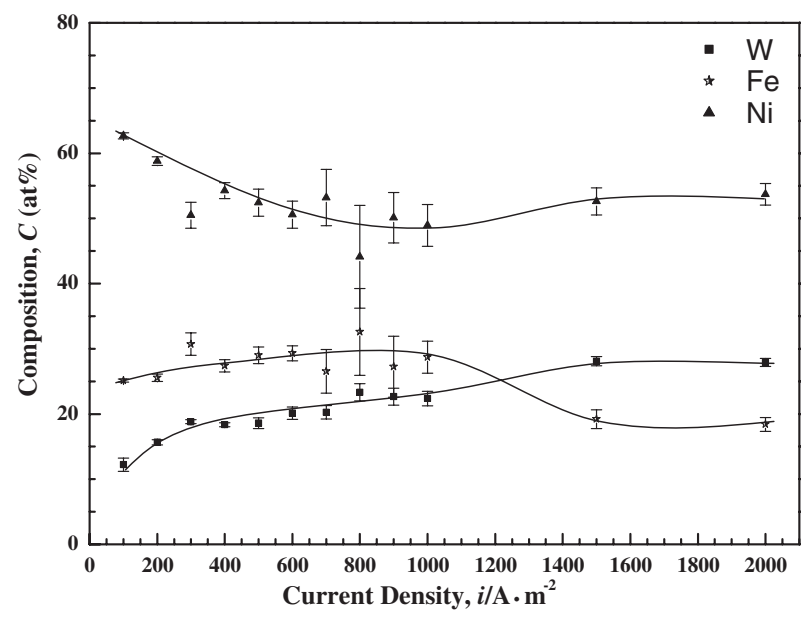

Fig. 1 Change in the composition of ternary Ni-Fe-W alloys with current density.

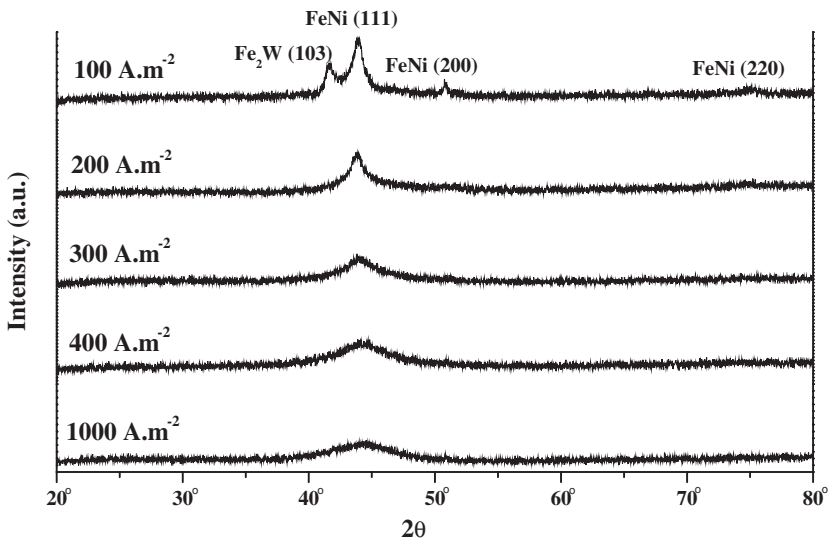

Fig. 2 X-ray diffraction patterns showing the change in structure with current density.

structure, with an increase in current density. The aparent grain sizes of the alloys were calculated by using Scherrer formula as given below:

$$
d=\frac{0.94 \lambda}{B \cdot \cos \theta}
$$

Where

$d=$ grain size,

$\lambda=$ wavelength of the $\mathrm{X}$-ray used, $\left(\mathrm{Cu}-\mathrm{K}_{\alpha}\right)$,

$\theta=$ diffraction angle,

and

$B=$ full width half maximum (FWHM) of X-ray diffraction peak (rad).

The results are shown in Fig. 3. The peak corresponding to FeNi (111) plane was used to calculate the grain size of the alloys. It is observed from Fig. 3 that the grain size decreases significantly from $7.7 \mathrm{~nm}$ for the alloy deposited at $100 \mathrm{~A} / \mathrm{m}^{2}$ to $2.0 \mathrm{~nm}$ for the alloy deposited at $400 \mathrm{~A} / \mathrm{m}^{2}$. No sharp change in the grain size is seen in the range from 400 to $2000 \mathrm{~A} / \mathrm{m}^{2}$. A slight variation of a few angstroms in apparent grain size observed in this current density range may be due to the change in the volume fraction of nanocrystalline phase.

The cathode current efficiency was calculated on the basis of the following formula:

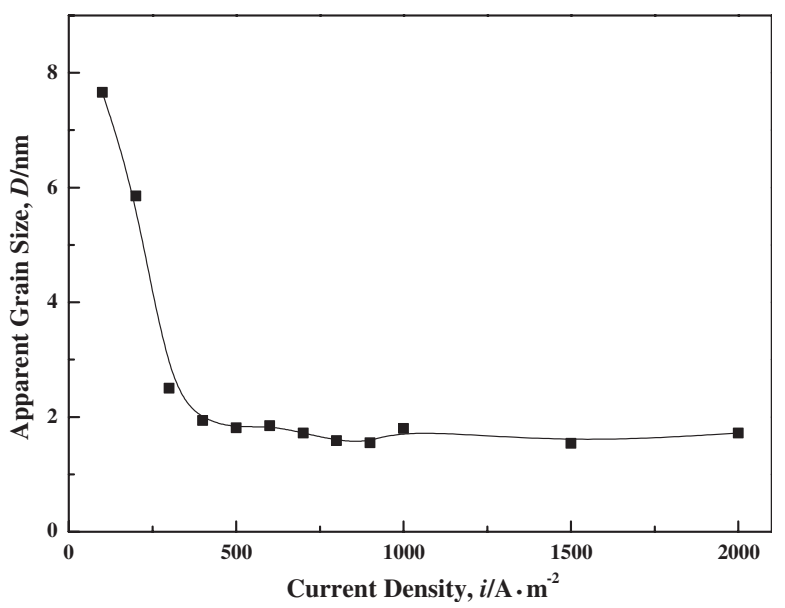

Fig. 3 Change in the apparent grain size of the deposited alloys with current density. 


$$
\eta=\frac{\delta w}{W_{\mathrm{o}}} \times 100
$$

where

$\delta w=$ mass of deposit measured experimentally,

$W_{\mathrm{o}}=$ mass of deposit if all the current is used in the deposition of alloy of same composition.

$W_{\text {o }}$ can be calculated as

$$
W_{\mathrm{o}}=\frac{I t}{F} \sum_{i=1}^{N} \frac{A_{i} M_{i}}{\sum_{j=1}^{N} A_{j} n_{j}}
$$

Here

$I=$ Total current applied (A)

$t=$ time duration of deposition (s)

$F=$ Faraday constant $=96485 \mathrm{C} \cdot \mathrm{mol}^{-1}$

$A_{i}=$ mole fraction of $i$ th element in the deposit

$M_{i}=$ atomic weight of $i$ th element

$n_{j}=$ valence number of $j$ th element $\left(n_{\mathrm{Ni}}=+2, n_{\mathrm{Fe}}=+2\right.$,

$\left.n_{\mathrm{W}}=+6, n_{\mathrm{P}}=+1\right)$

$N=$ total number of elements

Figure 4 shows cathode current efficiency as a function of current density. The relationship between current density and current efficiency is rather complicated. The current efficiency increases with an increase in current density from 100 to $300 \mathrm{~A} / \mathrm{m}^{2}$, remains nearly constant $(\sim 24 \%)$ up to $500 \mathrm{~A} /$ $\mathrm{m}^{2}$ and then decreases towards $1000 \mathrm{~A} / \mathrm{m}^{2}$. However, it again rises and reaches to $38 \%$ at $2000 \mathrm{~A} / \mathrm{m}^{2}$. Although the behavior is not simple to explain, it is confirmed that the highest current efficiency is obtained at $2000 \mathrm{~A} / \mathrm{m}^{2}$.

Table 2 summarizes hardness values of the deposits produced at different current densities. Hardness was measured by the UMIS-2000 nano-indentation system with Berkovich indenter from the surface of the sample. The system evaluates hardness, $\mathrm{H}$ from the load-penetration $(L-p)$ curves for loading and unloading cycles. The maximum applied load was $50 \mathrm{mN}$. The maximum penetration was about $700 \mathrm{~nm}$. It is observed that the hardness increases with increasing current density. The reduced Young's modulus $E /\left(1-v^{2}\right)$ was calculated from the initial unloading part of a

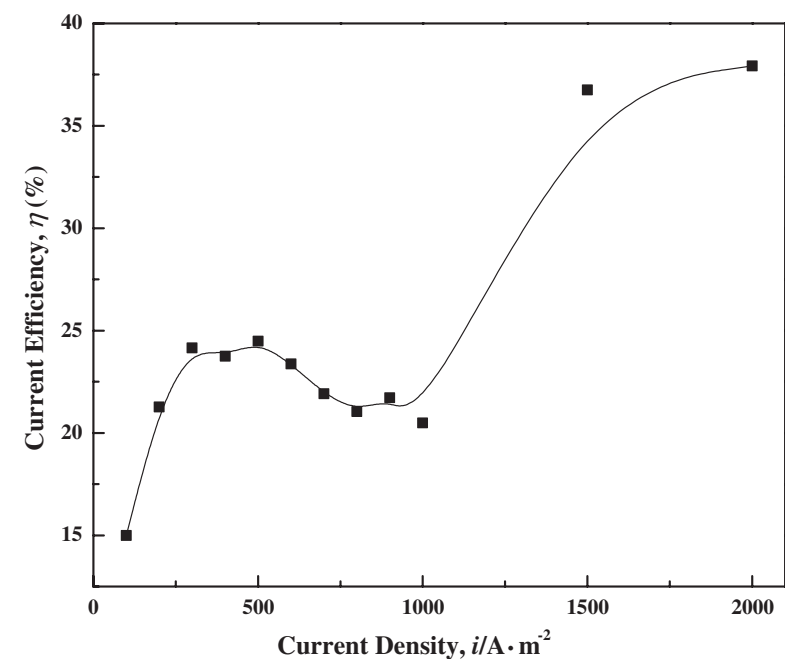

Fig. 4 Change in the cathode current efficiency of electrodeposition with current density for Ni-Fe-W alloys.
Table 2 Hardness, reduced Young's modulus and $H / E$ for the alloys prepared at different current densities.

\begin{tabular}{ccccc}
\hline $\begin{array}{c}\text { Current } \\
\text { density } \\
\left(\mathrm{A} \cdot \mathrm{m}^{-2}\right)\end{array}$ & $\begin{array}{c}\text { Berkovich } \\
\text { hardness, } H \\
(\mathrm{GPa})\end{array}$ & $\begin{array}{c}\text { Equivalent } \\
\text { Vicker's } \\
\text { hardness }\end{array}$ & $\begin{array}{c}\text { Reduced Young's } \\
\text { modulus, } E /\left(1-v^{2}\right)\end{array}$ & $H / E$ \\
\hline 200 & 6.85 & 629 & 197.2 & $4.17 \times 10^{-2}$ \\
400 & 7.17 & 658 & 192.6 & $4.44 \times 10^{-2}$ \\
600 & 7.81 & 717 & 172.6 & $5.29 \times 10^{-2}$ \\
800 & 7.87 & 723 & 198.6 & $4.74 \times 10^{-2}$ \\
2000 & 8.01 & 735 & 209 & $4.63 \times 10^{-2}$ \\
\hline
\end{tabular}

loading-unloading curve, as the displacement in this part is only due to elastic recovery. Table 2 also shows $H / E$ ratios for these alloys. The resistance to wear on the surface increases with increasing $H$ value, while the decrease in $\mathrm{E}$ value increases plastic deformation. The higher $H / E$ value means better mechnical properties of the film. It is also seen in Table 2 that the maximum value of $H / E$ is obtained for the $51 \mathrm{Ni}-29 \mathrm{Fe}-20 \mathrm{~W}$ alloy deposited at $600 \mathrm{~A} / \mathrm{m}^{2}$.

\subsection{Ni-Fe-W-P alloys}

It has been reported for $\mathrm{Ni}-\mathrm{W}$ system ${ }^{30)}$ that the addition of sodium hypophosphite to electroplating solution causes a sudden drop in tungsten content of the alloy as well as in cathode current efficiency (or deposition rate at constant current density). Therefore, in order to study the effect of sodium hypophosphite on Ni-Fe-W system, one should use experimental conditions corresponding to the preparation of an alloy with high tungsten content. Consequently, the current density of $2000 \mathrm{~A} / \mathrm{m}^{2}$, which corresponds to the alloy with the highest tungsten content $(54 \mathrm{Ni}-18 \mathrm{Fe}-28 \mathrm{~W})$ and the highest cathode current efficiency (38\%), was selected.

Figure 5 shows the effect of sodium hypophosphite content on the composition of tertiary Ni-Fe-W-P alloys. The addition of $0.01 \mathrm{~mol} / \mathrm{L}$ of sodium hypophosphite in the solution results in a rapid increase in the iron content of the alloy. Afterwards, however, it decreases with an increase in hypophosphite content. For nickel the behavior is just opposite. The tungsten content decreases and phosphorus content increases with an increase in the sodium hypophos-

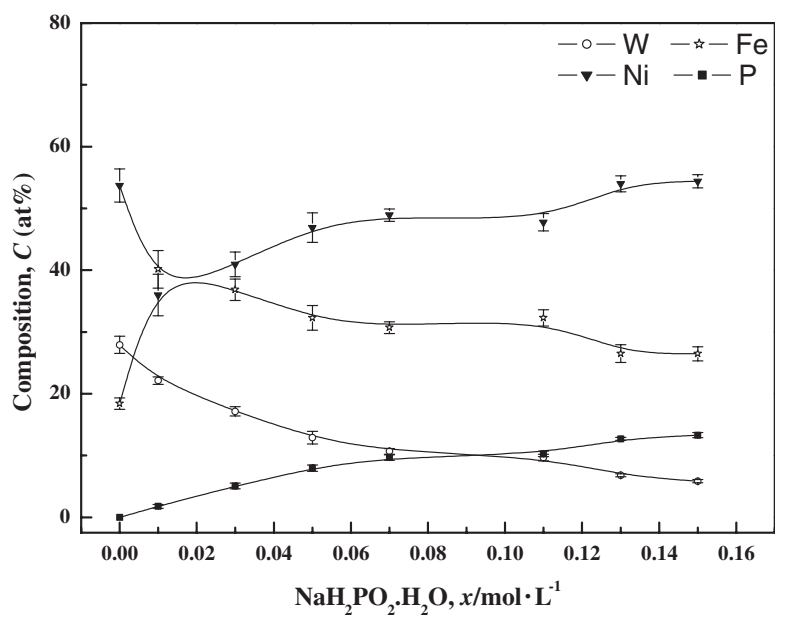

Fig. 5 Change in the composition of the Ni-Fe-W-P alloys deposited at $2000 \mathrm{~A} \cdot \mathrm{m}^{-2}$ with sodium hypophosphite. 


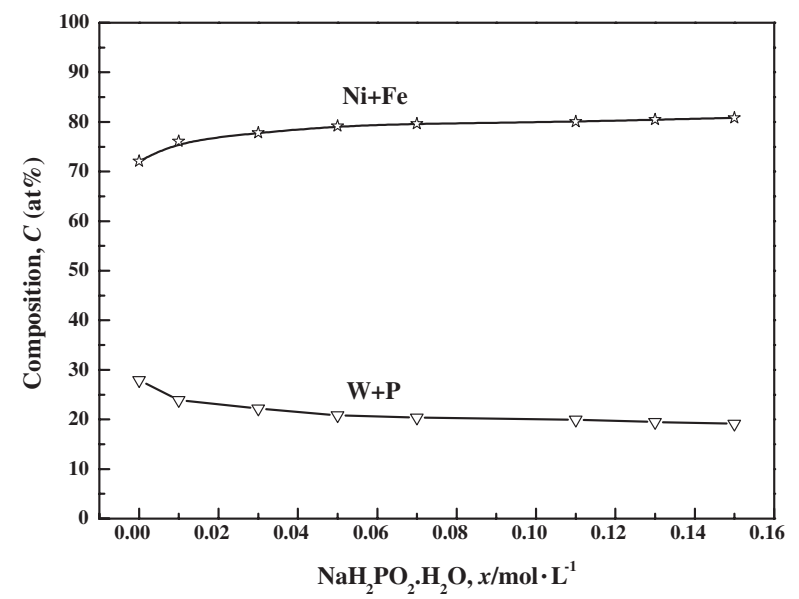

Fig. 6 Total amount of $\mathrm{W}+\mathrm{P}$ and $\mathrm{Ni}+\mathrm{Fe}$ in the Ni-Fe-W-P alloys as a function of sodium hypophosphite content.

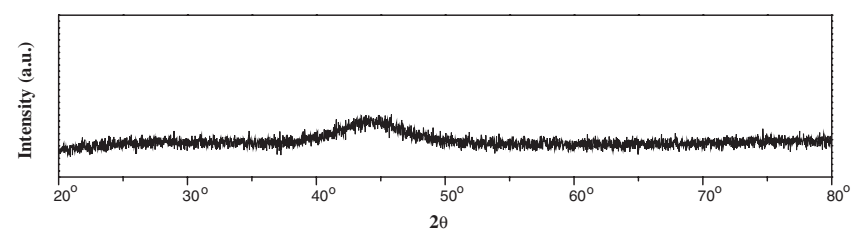

Fig. 7 X-ray diffraction pattern showing an amorphous structure of a tertiary alloy with composition of $43 \mathrm{Ni}-37 \mathrm{Fe}-12 \mathrm{~W}-8 \mathrm{P}$.

phite content of the plating solution. An important point to note is that the effect of sodium hypophosphite on tungsten content is not so drastic as it has been observed for Ni-W-P system. The addition of iron is, therefore, useful in this respect and these plating solutions do not require careful control of bath composition as it is necessary for Ni-W-P system.

Another important point is the total content of tungsten and phosphorus in the alloy, which remains constant except for alloys deposited from solutions containing very low hyposphosphite contents $(<0.03 \mathrm{~mol} / \mathrm{L})$ (Fig. 6). Therefore, the increase in phosphorus content is at the cost of tungsten content and the increase in nickel content is at the cost of iron content.

The structure of the Ni-Fe-W-P alloys as determined by $\mathrm{XRD}$ is amorphous. A typical XRD pattern is shown in Fig. 7, which corresponds to $43 \mathrm{Ni}-37 \mathrm{Fe}-12 \mathrm{~W}-8 \mathrm{P}$ alloy. The variation of the cathode current efficiency with sodium hypophosphite content is shown in Fig. 8. One can see a continuous decrease in cathode current efficiency with an increase in sodium hypophosphite content. The initial drop in the current efficiency is very fast from no sodium hypophosphite to $0.01 \mathrm{~mol} / \mathrm{L}$ and from $0.01 \mathrm{~mol} / \mathrm{L}$ to $0.03 \mathrm{~mol} / \mathrm{L}$. From $0.03 \mathrm{~mol} / \mathrm{L}$ to onward it drops more or less with a constant slope.

\section{Discussion}

As shown in Fig. 1, tungsten content increases with increasing current density. Tungsten is a metal which cannot be deposited alone from aquous solutions. When codeposited with iron group elements, its induced deposition takes place.

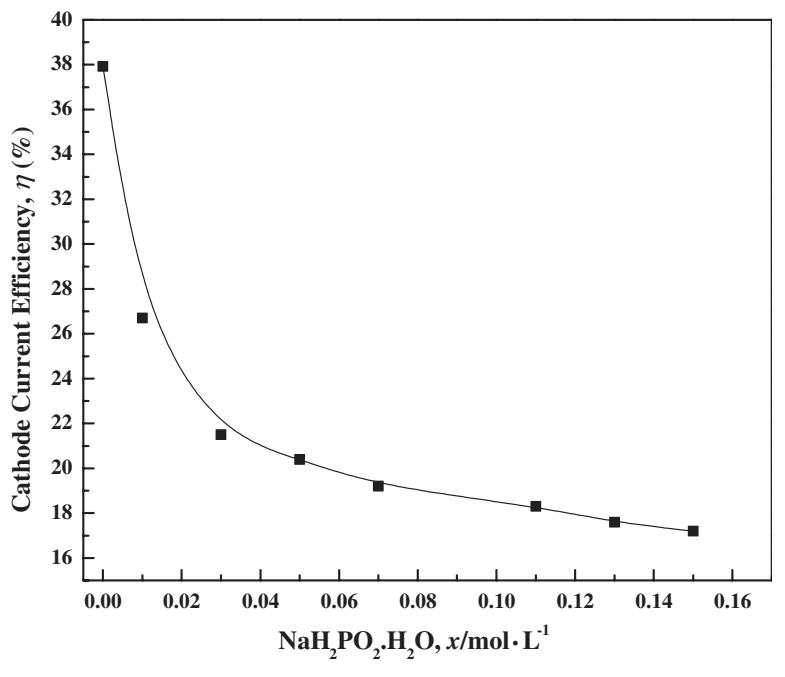

Fig. 8 Relation between cathode current efficiency and sodium hypophosphite content for the Ni-Fe-W-P alloys.

The deposition of tungsten with iron group elements takes place at potentials nobler than those required for the deposition of iron group elements alone. ${ }^{31)}$ However, in general, as the current density increases, the tungsten content of the alloys increases up to a specific upper limit. On the other hand, mutual codeposition of iron group elements is anomalous under many conditions, ${ }^{32)}$ implying that nobler element deposits preferentially at higher current densities. In the normal deposition process, nobler element should deposit preferentially at lower current densities and the higher current density condition should favour the deposition of less noble element. That is why the deposition of iron, which has lower standard electrode potential $(-0.44 \mathrm{~V})$ than nickel $(-0.25 \mathrm{~V})$, is suppressed at higher current densities. This anomaly is lost by the addition of a very small amount of sodium hypophosphite as shown in Fig. 5, though an increase in sodium hypophosphite content is again accompanied by a decrease in iron content and increase in nickel content of the alloys. The reason for sudden loss of anomaly by the addition of sodium hypophosphite is not clear at present and further study is required to clarify this phenomenon.

Figure 5 shows the decrease in the tungsten content of NiFe-W-P alloys by the addition of sodium hypophosphite. The decrease is not sharp as that observed for Ni-W-P alloys. ${ }^{30)}$ $\mathrm{Up}$ to $0.03 \mathrm{~mol} / \mathrm{L}$ of sodium hypophosphite, there is a decrease in overall molar content of tungsten and phosphorus. When sodium hypophosphite content increases beyond $0.03 \mathrm{~mol} / \mathrm{L}$, the total molar content of tungsten and phosphorus remains constant (Fig. 6). In this range, the increase in molar phosphorus content is equal to the decrease in molar tungsten content. Total molar content of both is 20 molar percent.

Since $\mathrm{H}_{2} \mathrm{PO}_{2}{ }^{-1}$ ions are lighter than the complex formed between $\mathrm{Ni}$ or $\mathrm{Fe}$ and $\mathrm{W}$ with citrate and ammonia ions, the former diffuses at a faster rate than the latter and is concentrated in the double layer. In this way they hinder the diffusion of complex ions and in order for the current to flow, potential drops on the cathode and this allows the deposition of uncomplexed nickel ions. We have observed during experiments that deposition potential from sodium 


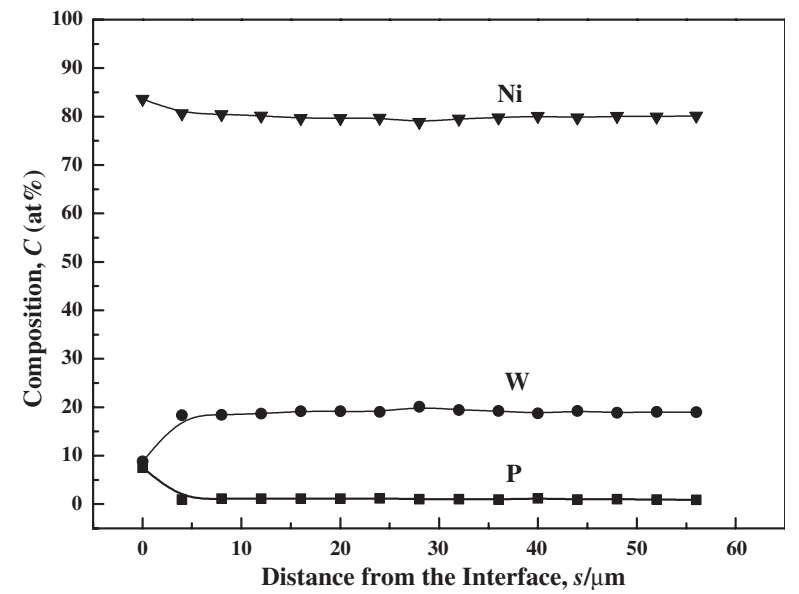

Fig. 9 Composition in the cross section of the Ni-W-P alloy as a function of distance from the interface.

hypophosphite containing baths is lower than that from baths having less or no sodium hypophosphite. $\mathrm{H}_{2} \mathrm{PO}_{2}{ }^{-1}$ ions are then adsorbed on newly formed nickel surface and their reduction takes place. If the solution has less amount of $\mathrm{H}_{2} \mathrm{PO}_{2}^{-1}$ ions, then they will be depleted in the vicinity of cathode surface soon after the start of electrodeposition process and this will allow the complex ions to reach surface and be reduced. In this case hypophosphite ions will also be reduced due to the diffusion from bulk solution, but, due to insufficient supply, will not be able to fully occupy the surface of the cathode by adsorption and hinder the reduction of tungsten ions. The diffusion will then take place on a steady rate and composition will become constant. However, at initial stages, the composition should be different from overall composition. It was confirmed in Ni-W-P system. A typical diagram showing the variation of composition along the cross section for an alloy deposited from a solution containing very low concentration of sodium hypophosphite is shown in Fig. 9. Nickel surface seems to be very favorable for the adsorption and reduction of $\mathrm{H}_{2} \mathrm{PO}_{2}{ }^{-1}$ ions. If sufficient supply of these ions is available, it can completely hinder the reduction of tungsten. Addition of iron seems to change the kinetics of the process either by changing the nature of the film surface or by modifying the double layer structure. It reduces the tendency of $\mathrm{H}_{2} \mathrm{PO}_{2}{ }^{-1}$ ions to hinder the deposition of tungsten ions. The idea of a specific role of iron is also enforced by similar shape of the variation mode of iron and tungsten compositions with hypophosphite content in Fig. 5. Also the processes of deposition of tungsten and phosphorus have some correspondance, such that either tungsten ion or $\mathrm{H}_{2} \mathrm{PO}_{2}^{-1}$ ion is reduced. That is why total molar content remains constant. In such case, the decrease in current efficiency should correspond to the replacement of $\mathrm{W}^{+6}$ ion with $\mathrm{P}^{+}$. In order to check this idea, it was assumed that an alloy containing 20 at $\% \mathrm{~W}$ has a current efficiency of $23 \%$. Then 5 at $\%$ of $\mathrm{W}$ was replaced with $\mathrm{P}$, with the remaining $\mathrm{W}$ being at 15 at $\%$. Since the reduction of one $\mathrm{W}^{+6}$ ion consumes six times more electrons than that of $\mathrm{P}^{+}$, five of these electrons will be lost in some useless reaction. It will result in a decrease in current efficiency. The change in current efficiency was calculated by replacing different

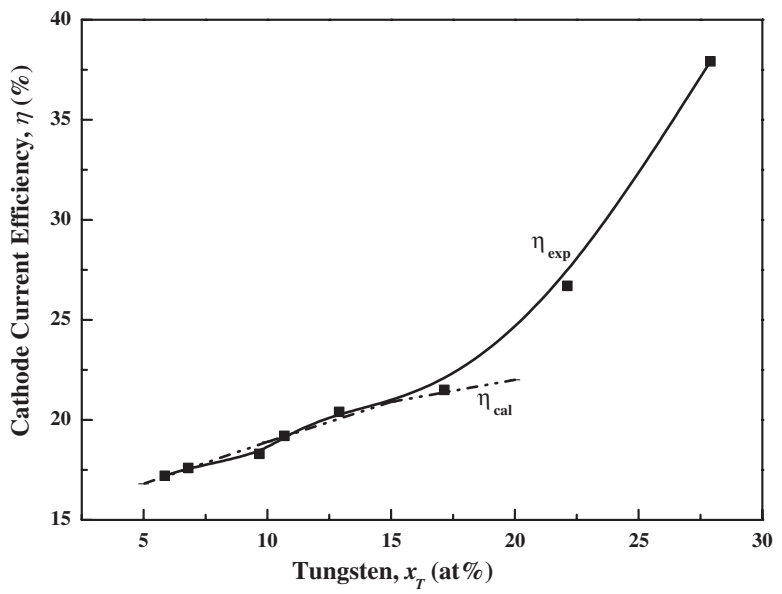

Fig. 10 Relation between tungsten and cathode current efficiency for the Ni-Fe-W-P alloys: $\eta_{\text {cal }}=$ calculated current efficiency in the assumption that efficiency change is due to replacement of $\mathrm{W}$ atoms with $\mathrm{P}$ atoms, $\eta_{\exp }$ $=$ experimentally determined current efficiency.

amounts of $\mathrm{W}$ with $\mathrm{P}$ and the results were plotted as a function of tungsten content. The dashed line in Fig. 10 represents the calculated effeciency, while the solid curve denotes experimental results. It is found that this line very accurately predicts the change in current efficiency. Therefore, the addition of hypophosphite is associated with the incorporation of $\mathrm{H}_{2} \mathrm{PO}_{2}^{-1}$ ions in the solution which replace $\mathrm{W}^{+6}$ ions with $\mathrm{P}^{+}$ions in the reduction reaction. However, these ideas are required to be explored further.

\section{Conclusions}

(1) Tungsten content of ternary Ni-Fe-W alloys increases with an increase in current density. The structure is nanocrystalline at low current densities and the grain size decreases with an increase in current density, such that at higher current densities an amorphous phase forms.

(2) Cathode current efficiency for Ni-Fe-W alloys has a complicated behavior with current density, but it increases to a sufficiently high value of $38 \%$ at current densities of 1500 to $2000 \mathrm{~A} / \mathrm{m}^{2}$.

(3) The alloy deposited at $600 \mathrm{~A} / \mathrm{m}^{2}$ having a composition of $51 \mathrm{Ni}-29 \mathrm{Fe}-20 \mathrm{~W}$ shows the best mechnical properties among all Ni-Fe-W alloys prepared.

(4) The addition of phosphorus to Ni-Fe-W-P alloys is accompanied by a decrease in tungsten content of the alloys. An interesting feature of these alloys is that the total molar concentration of tungsten and phophorus remains constant for alloys deposited from solutions containing sodium hypophosphite more than $0.03 \mathrm{~mol} /$ $\mathrm{L}$, though phosphorus content increases with an increase in hypophosphite content of the plating solution.

(5) The current efficiency for Ni-Fe-W-P alloys decreases with an increase in phosphorus content. For the alloys deposited from solutions containing sodium hypophosphite more than $0.03 \mathrm{~mol} / \mathrm{L}$, the decrease in current efficiency is due to the replacement of $\mathrm{W}$ atoms with $\mathrm{P}$ atoms. 
(6) There is no sharp change in the tungsten content of NiFe-W-P alloys with change in hypophosphite content, as it has been observed for ternary Ni-W-P alloys.

\section{Acknowledgements}

The authors are thankful to Mr. Yoshihiro Murakami for his assistance in doing EPMA analysis and Dr. Hidemi Kato for his assistance in nano-indentor hardness measurements.

\section{REFERENCES}

1) A. Inoue, M. Matsushita, Y. Kawamura, K. Amiya, K. Hayashi and J. Koike: Mater. Trans. 43 (2002) 580-584.

2) T. Zhang and A. Inoue: Mater. Trans. 43 (2002) 708-711.

3) A. Inoue, Y. Kawamura, M. Matsushita and K. Hayashi: Mater. Sci. Forum 386 (2002) 509-517.

4) A. Inoue, W. Zhang, T. Zhang and K. Kurosaka: Acta Mater. 49 (2001) 2645-2652.

5) Y. Kawamura, K. Hayashi, J. Koike, A. Kato, A. Inoue and T. Masumoto: Mater. Sci. Forum 350 (2000) 111-116.

6) S. Pang, T. Zhang, K. Asami and A. Inoue: Mater. Trans. 43 (2002) 2137-2142.

7) S. Pang, T. Zhang, K. Asami and A. Inoue: Mater. Trans. 43 (2002) 1771-1773.

8) S. Pang, T. Zhang, K. Asami and A. Inoue: Corros. Sci. 44 (2002) 18471856.

9) M. Mehmood, B.-P. Zhang, E. Akiyama, H. Habazaki, A. Kawashima, K. Asami and K. Hashimoto: Corros. Sci. 40 (1998) 1-17.

10) M. Mehmood, E. Akiyama, H. Habazaki, A. Kawashima, K. Asami and K. Hashimoto: Corros. Sci. 41 (1999) 1871-1890.

11) M. Mehmood, E. Akiyama, H. Habazaki, A. Kawashima, K. Asami, K. Hashimoto: Corros. Sci. 42 (2000) 361-382.
12) A. Inoue, T. Zhang and A. Takeuchi: Appl. Phys. Lett. 71 (1997) 464466.

13) A. Inoue and BL. Shen: Mater. Trans. 43 (2002) 766-769.

14) A. Inoue and BL. Shen: Mater. Trans. 43 (2002) 2350-2353.

15) J. Ahmad, K. Asami, A. Takeuchi, Dmitri. V. Louzguine and A. Inoue: Mater. Trans. 44 (2003) 911-916.

16) BL. Shen, H. Kimura and A. Inoue: Mater. Trans. 43 (2002) 589-592.

17) DH. Shin, H. Niedoba, Y. Henry, F. Machizaud, V. Brien, D. Chumakov, R. Schafer and G. Suran: J. Magn. Magn. Mater. 249 (2002) 422-427.

18) H. Koshiba and A. Inoue: Mater. Trans. 42 (2001) 2572-2575.

19) BL. Shen, H. Koshiba, A. Inoue, H. Kimura and T. Mizushima: Mater. Trans. 42 (2001) 2136-2139.

20) H. Habazaki, M. Yamasaki, A. Kawashima and K. Hashimoto: Appl. Organomet. Chem. 14 (2000) 803-808 (Sp. Iss. SI).

21) M. Yamasaki, H. Habazaki, K. Asami and K. Hashimoto: J. Electrochem. Soc. 147 (2000) 4502-4506.

22) M. Yamasaki, M. Komori, E. Akiyama, H. Habazaki, A. Kawashima, K. Asami and K. Hashimoto: Mat. Sci. Eng. A-Struct. 267 (1999) 220226.

23) H. Habazaki, T. Yoshida, M. Yamasaki, M. Komori, K. Shimamura, E. Akiyama, A. Kawashima and K. Hashimoto: Stud. Surf. Sci. Catal. 114 (1998) 261-266.

24) T. Yamasaki, R. Tomohira, Y. Ogino, P. Schlobmacher and K. Ehrlich: Plat. Surf. Finish. 87 (2000) 148-152.

25) Yamasaki, P. Schlobmacher, K. Ehrlich and Y. Ogino: Nanostruct. Mater. 10 (1998) 375-388.

26) M. Donten: J. Solid State Electrochem. 3 (1999) 87-96.

27) R.L. Zeller, U. Landau: J. Electrochem. Soc. 137 (1990) 1107-1111.

28) L.E. Vaaler and M.L. Holt: J. Electrochem. Soc. 90 (1946) 43.

29) T. Yamasaki: Scr. Mater. 44 (2001) 1497-1502.

30) J. Ahmad, K. Asami, A. Takeuchi and A. Inoue: Mater. Trans. 44 (2003) 705-708.

31) A. Brenner: Electrodeposition of Alloys-II, (1963) 399.

32) A. Brenner: Electrodeposition of Alloys-I, (1963) 77. 